\section{Autonomous remanufacturing}

\author{
F. Javier Ramírez ${ }^{1}$ - Marco Castellani ${ }^{2} \cdot$ Wenjun $\mathrm{Xu}^{3}$ \\ Published online: 5 June 2020 \\ (C) Springer-Verlag London Ltd., part of Springer Nature 2020
}

\section{Introduction}

The availability of several raw materials has become a growing concern within the last few decades [1], whilst the generation of waste materials has significantly increased [2]. As a result, the adoption and implementation of end-of life (EoL) strategies to save raw materials, manufacturing costs and energy consumption has become one of the major concerns for governments, policymakers, industrialists and researches around the world. In this context, remanufacturing has become a widely investigated research topic.

Defined by [3] as "the process of returning a used product to at least its Original Equipment Manufacturer's (OEM) performance specification from the customers' perspective, and giving the resultant product a warranty that is at least equal to that of a newly manufactured equivalent", remanufacturing is recognised as a new type of industry with great potential in the twenty-first century [4] and considered one of the future trends of the manufacturing industry [5]. Remanufacturing plays a key role as an EoL strategy, potentially able to increase the firm's profitability, create new job opportunities, and reduce environmental impacts [6].

Disassembly is "the process of systematic removal of desirable constituents (components and/or materials) from the

F. Javier Ramírez

FranciscoJ.Ramirez@uclm.es

Marco Castellani

M.Castellani@bham.ac.uk

Wenjun Xu

xuwenjun@whut.edu.cn

1 School of Industrial Engineering, Universidad de Castilla-La Mancha, Albacete, Spain

2 Department of Mechanical Engineering, University of Birmingham, Birmingham, UK

3 School of Information Engineering, Wuhan University of Technology, Wuhan, China original assembly so that there is no impairment to any useful constituent" [7]. Because the components must be disassembled prior to remanufacturing, disassembly is a critical and unavoidable step in the reprocessing of EoL products. Disassembly planning is the first consideration in each remanufacturing process [8]. Disassembly planning is focused on designing a detailed plan for removing specific components or sub-assemblies from a whole product or assembly [9]. It is a comprehensive field of research covering three main sub-problems: Disassembly Sequence Planning [10], Disassembly Line Balancing [11] and Disassembly Path Planning [12].

Disassembly operations are traditionally performed by humans. However, due to their complexity, low efficiency, and long times and costs, they are ideal candidates for automation. Automation is particularly desirable and economically viable in the disassembly of large and complex products [13], and when the operations and materials involved imply a hazard for the operator. In this context, robotic disassembly [14], cognitive robotics [15] and human-robot collaboration in remanufacturing [16] are promising avenues in disassembly processes for remanufacturing.

This special issue focuses on autonomous remanufacturing. Specifically, we encourage contributions that deal with new models, methodologies, techniques, experimental applications and/or advanced remanufacturing systems to extend the stateof-the-art in remanufacturing in terms of novel approaches, with significant impact in the remanufacture domain.

\section{Invited contributions}

Submissions to this special issue are encouraged from all theoretical and experimental perspectives drawing in autonomous remanufacturing, namely disassembly planning, robotic disassembly, human-robot collaboration, collaborative robots and others. Authors must clearly outline why their research is new and interesting for research and practice and how it relates to the theme of this special issue. 
We invite submissions in all areas focused on the theme of "Autonomous Remanufacturing", including but not limited to the following list of topics:

- Robotic disassembly

- Human-robot interaction

- Collaborative robots

- Robotic inspection and testing

- Disassembly sequence planning

- Disassembly line balancing

- Disassembly path planning

- Disassembly mechanisms

- Disassembly re-planning

- Evolutionary optimization

- Optimisation methods for remanufacturing

\section{Submissions guidelines}

Please submit papers vsia the journal's online submission system (https://www.editorialmanager.com/jamt/). To indicate submission to this Special Issue, please select "S.I.: Autonomous Remanufacturing" from the drop-down menu on the page labelled "Additional Information". Please observe the instructions regarding the format and size of contributions to The International Journal of Advanced Manufacturing Technology.

All papers will be reviewed anonymously (double-blind process) by at least two referees with regard to relevance, originality and research quality. In addition to the editors of this special issue, distinguished international scholars will be involved in the review process.

\section{Important dates}

- Paper submission opens: June 1, 2020

- Deadline for paper submission: February 28, 2021

\section{Compliance with ethical standards}

Conflict of interest The authors declare that they have no conflict of interest.

\section{References}

1. Fellner J, Lederer J, Scharff C, Laner D (2017) Present potentials and limitations of a circular economy with respect to primary raw material demand. J Ind Ecol 21(3):494-496

2. United Nations (2017) United Nations Environmental Programme (UNEP). Tech. rep., United Nations. URL: https://www.unep.org/ es.

3. Matsumoto M, Ijomah W (2013) Remanufacturing. In: Handbook of Sustainable Engineering. Springer, pp. 389-408

4. Xia X, Zhu H, Zhang Z, Liu X, Wang L, Cao J (2020) 3D-based multi-objective cooperative disassembly sequence planning method for remanufacturing. Int J Adv Manuf Technol 106(9):4611-4622

5. ERN (2017) The European Remanufacturing Network- coordinating and supporting European remanufacturers. Tech. rep., European Remanufacturing Network

6. D'Adamo I, Rosa P (2016) Remanufacturing in industry: advices from the field. Int J Adv Manuf Technol 86(9-12):2575-2584

7. Kongar E, Gupta SM (2006) Disassembly sequencing using genetic algorithm. Int J Adv Manuf Technol 30(5-6):497-506

8. Parsa S, Saadat M (2019) Intelligent selective disassembly planning based on disassemblability characteristics of product components. Int J Adv Manuf Technol 104(5-8):1769-1783

9. Lambert AJ (2003) Disassembly sequencing: a survey. Int J Prod Res 41(16):3721-3759

10. Zhou Z, Liu J, Pham DT, Xu W, Ramirez FJ, Ji C, Liu Q (2019) Disassembly sequence planning: recent developments and future trends. Proc Inst Mech Eng B J Eng Manuf 233(5):1450-1471

11. Özceylan E, Kalayci CB, Güngör A, Gupta SM (2019) Disassembly line balancing problem: a review of the state of the art and future directions. Int J Prod Res 57(15-16):4805-4827

12. Ghandi S, Masehian E (2015) Review and taxonomies of assembly and disassembly path planning problems and approaches. Comput Aided Des 67:58-86

13. Ramírez FJ, Aledo JA, Gamez JA, Pham DT (2020) Economic modelling of robotic disassembly in end-of-life product recovery for remanufacturing. Comput Ind Eng 142:106,339

14. Liu J, Zhou Z, Pham DT, Xu W, Yan J, Liu A, Ji C, Liu Q (2018) An improved multi-objective discrete Bees algorithm for robotic disassembly line balancing problem in remanufacturing. Int $\mathrm{J}$ Adv Manuf Technol 97(9-12):3937-3962

15. Vongbunyong S, Kara S, Pagnucco M (2013) Application of cognitive robotics in disassembly of products. CIRP Ann Manuf Technol 62(1):31-34

16. Xu W, Tang Q, Liu J, Liu Z, Zhou Z, Pham DT (2020) Disassembly sequence planning using discrete Bees algorithm for human-robot collaboration in remanufacturing. Robot Comput Integr Manuf 62: 101,860

Publisher's note Springer Nature remains neutral with regard to jurisdictional claims in published maps and institutional affiliations. 